\title{
The Effect of Firm's Growth on Firm Survival in Vietnam
}

\author{
Nguyen Minh $\mathrm{Ha}^{1}$ \\ ${ }^{1}$ Graduate School, Ho Chi Minh City Open University, Vietnam \\ Correspondence: Nguyen Minh Ha, Graduate School, Ho Chi Minh City Open University, 97 Vo Van Tan Street, \\ District 3, Ho Chi Minh City, Vietnam. Tel: 84-8-3930-0947. E-mail: ha.nm@ou.edu.vn or ngmiha@yahoo.com
}

\author{
Received: March 4, $2013 \quad$ Accepted: March 18, $2013 \quad$ Online Published: April 17, 2013 \\ doi:10.5539/ibr.v6n5p142 URL: http://dx.doi.org/10.5539/ibr.v6n5p142
}

\begin{abstract}
With the dataset of 7,962 firms in Vietnam and using the Cox proportional hazard model, the main findings are drawn that the relationship between the firm's growth (both in employment and in assets) and the survival is positive and non-linearity, and as increasing the growth, the effect of firm's growth on the firm survival is diminishing. In addition, we also find that the presence of the domestic private and the foreign firms can improve the survival chances, compared to the state firms; The firm size in assets and initial debt have positive relationships with firm survival; Earning before taxes over labour in year $t-1$ and the return on assets in year $t-1$ are important and have positive impacts on firm survival in year $t$, whereas the leverage in year $t-1$ has a negative impact on the probability of survival in year $t$ for firms in Vietnam.
\end{abstract}

Keywords: Cox, exit, firm, growth, hazard, survival, Vietnam

\section{Introduction}

Factors that influence the birth and death of firms and the duration of firm survival in developed countries have attracted much attention from researchers in recent years (Parker, 2004; Strotmann, 2006). However, studies of firms' survival in developing countries are less common (Parker, 2004), and, to date, there has been a scarcity of work directly studying the survival of new start-up firms in developing countries. In particular, these studies are quite rare in a transition economy, like that of Vietnam, which has undergone some changes in the past two decades. Vietnam is in transition from being a centrally-planned economy to being a market economy, and the recognition and appearance of domestic private and foreign owned firms in the economy is part of this transition process. The domestic private and foreign firms have confronted more difficulties from government policies, as well as from the market, when compared to firms under state ownership. Hence, this is an interesting period in which to investigate firms in Vietnam.

In understanding firm survival, many econometric models have been used. Hazard models, in particular, have been widely employed in studies in the developed world, but in the developing world the use of hazard models is still very limited (Nkurunziza, 2005). In this research, a hazard model is applied to investigate newly set-up firms in a developing world context and this, to my knowledge, is the first hazard model for studying the survival of new start-up firms in Vietnam with a new panel data.

The purpose of this paper is to analyze the effect of firm's growth on the survival of new Vietnamese start-up firms. The method applied in this paper is the Cox partial likelihood estimation for the proportional hazards model. The database used is drawn randomly from the result of annual surveys conducted by the Vietnam General Statistical Office. The data is the firm-level panel data in Vietnam covering the period from 2000-2005, consisting of 10,000 firms. After filtering by criteria such as outliers, lost data, etc., there are 7,962 qualified firms.

The remainder of this paper is organized as follows: The next section gives a brief literature review. Section 3 describes the data used, and Section 4 presents the empirical methodology. Section 5 gives a statistical summary description of the data. Section 6 presents the empirical results of the Cox proportional hazard model. Finally, Section 7 concludes the paper and draws some policy implications that can inform policy in regards to supporting firm survival.

\section{Brief Literature Review}

Jovanovic's (1982) learning model assumes that factors are supplied at a constant price, that the product is 
homogeneous, and that the time-path of the demand for the product is deterministic and known. Firms and potential firms know the entire equilibrium price sequence and rely upon it to make decisions of entry, production, and exit. The number of firms in the industry is infinite; each firm is very small to affect the price. The path of output prices is a deterministic and self-fulfilling equilibrium. Various firms have different and random costs, and the distribution of true costs for all firms is known to each firm, but no firm is sure of its own true cost. Each firm has its own belief about its true costs level when entering the market, and, as each period passes, based on previous outcomes and possibilities, each firm updates its beliefs about its true costs. Some firms are more efficient than others at all levels of output.

The firm's growth will influence the failure rate; namely, failure rates should be a decreasing function of firm growth and firm size. In other words, growth decreases average costs and increases efficiency, thus improving the likelihood of survival. The positive relationship of firm growth and survival is found empirically by other studies, such as those by Mata Portugal and Guimaraes (1995), Audretsch (1995), McPherson (1995), Fotopoulos and Louri (2000a and 2000b), Mata and Portugal (2002), and Persson (2004). Therefore, the first hypothesis is that firm's growth has a positive effect on firm survival or negative effect on hazard rate of firms (Hypothesis 1).

Jovanovic's (1982) model also shows that the output is decreasing in $x\left(x_{t}\right.$ is the information received prior to $\left.t\right)$ and $x_{t+1}=x_{t}\left(1+u_{t}\right)$, where $u_{t}$ is error terms and has a mean of zero. $x_{t} x_{t+1}$ is convexity; thus, for mature firms that survive for a long time, $x_{t}$ converges to a constant. This means that the variance of $u_{t}$ declines as the firm becomes more nature; younger firms have more variability in their growth rates and grow faster than the older firms. Hence, the smaller firms should have higher and more variable growth rates, and they are more likely to fail. As Evans (1987a and 1987b) and Dunne, Roberts and Samuelson (1989) illustrate, firm growth declines at a diminishing rate to firm size. These imply that when the firm becomes larger, its growth declines; thus, the effect of growth on firm survival diminishes over time.

This is in accordance with some theories and models of firm growth. The theory of firm growth reported by Penrose (1959) is that the firm's growth rate changes with an increase in its size, and there is a maximum growth rate for the firm under the given circumstances. After reaching a maximum point, the growth rate tends to diminish because growth is restricted by the firm's productive opportunity. The productive opportunity is limited to the extent to which the firm realizes that high growth will not be efficient, or the extent to which it does not see opportunities for expansion. Spence's (1979) model states that, in the growing stage of the evolutionary process, after reaching the optimal penetration of the market, the firm will grow at a lower rate. In Nelson and Winter's (1978) model, when the firm has reached a certain size, it becomes larger and will restrain its growth to avoid a decrease in price and an average growth rate that first increases and then flattens out, or declines, with firm size. Thus, we can hypothesize on the effect of growth on survival over time that As growth increases, the positive effect of growth on survival diminishes (Hypothesis 2).

Based on Jovanovic's (1982) learning model, two hypotheses above are outlined in this paper. To test hypothesis 1 , growth is measured by the proportionate change in employment and assets, and the coefficients of growth in the hazard model are expected to be negative (i.e. they are positive to the survival). For hypothesis 2, variables of growth are squared, and it is estimated that their coefficients in the hazard model have positive signs, meaning that the impact of growth on survival deceases as growth increases. Hence, non-linearity exists between growth and firm survival.

Firm survival is affected not only by growth, but also by other factors. In this research, other factors that affect firm survival are considered, including: differences in types of firms, differences in the economic sector, initial founding conditions, productivity, profitability, and leverage. Productivity, profitability, and leverage are analysed in the previous period (year $t-1$ ) to affect the probability of survival in the current year (year $t$ ). Therefore, in addition to the hypotheses of growth's effect on firm survival, we also give hypotheses concerning the effects of other determinants on firm survival, as follows: There are significantly different survival rates among different types of firms (or different ownerships); Firms operating in different economic sectors have different survival rates; Firms with larger scales at start-up time have longer lifetimes; Firms able to gain access to initial funds have more likelihood of survival; Capital intensity has a positive effect on firm survival; Firms with higher productivity are able to stay in the market longer; The higher profitability (higher ROS and ROA) firms have, the longer they survive; After entering the market, firms with higher debt are more likely to fail.

All of the above hypotheses will be tested by empirical study in this paper in order to determine the effects of firm's growth and other determinants on firm survival in Vietnam. 


\section{Data of Study}

The main data for my paper is from the firm-level database, which is the result of surveys conducted annually by the Vietnam General Statistical Office. Such data from Vietnamese firms is currently available from the years 2000 to 2005.

Vietnam is a developing country with a transition economy where the information system is very weak and, in particular, information about firms is very rare. Thus, at present, this data is the only source in Vietnam which provides longitudinal data in order to analyze the post-entry performance and duration of new firms. It is this new data set concerning firms that can monitor firms throughout several years in Vietnam.

Some definitions need to be distinguished in the data: i) The database has many records (many firms), and each firm identified is established by the Vietnamese Laws of Enterprises with its own tax code. This does not include household firms (this kind of household firm is not provided a tax code) because the tax code is a basis for monitoring the firm over the years. ii) Firms defined as 'entry' firms appear first in the database. For firms that start up before the year 2000, the year of 'entry' and the year of 'start-up' are different. This is the case for firms established prior to 2000 and their start-up times are known. For firms that were set up from the year 2000 and beyond, the year of 'entry and the year of 'start-up' are the same. iii) Firms defined by 'death,' 'exit,' or 'failure' in the market disappear from the database and never return. iv) The year is used as the unit of discrete time, and each time unit (one year) is viewed as a trial.

The criteria for filtering the data are below: (i) Firms that disappear and reappear in the database are dropped from the sample. This phenomenon may be explained by losing information about the firm or by the firm's halting operation for some various reasons. (ii) Alternatively, some firms are dropped when they are identified as entering at year $t$, but there is no information about them at year $t$. It may be that these firms were set up in the months at the end of the calendar year, and they began to operate at the beginning of the next year; thus no information about them is available for the start-up year. (iii) Alternatively, some firms are also deleted from the dataset when their information is lost in any particular year. This may be caused by a loss of information in collecting or inputting data.

Firms are drawn randomly from the total database, making the sample for this study a random one. The number of subjects for this research is 10,000 firms. After filtering unqualified firms according to the above criteria, the total number of subjects is 7,962 firms, which enter the sample from 2000-2005. All firms are monitored until 2005.

In the dataset, each time unit is a year and the time is considered discrete time. Each firm has many observations and each observation is corresponds to each time that a firm is at risk of failure. Thus, for each firm, there are as many data rows (each row is for an observation) as there are time intervals at the risk of the event occurring for each firm. Corresponding to each time (each observation) are both time invariant covariates and time-varying covariates. Hence, the dataset for this research is an unbalanced panel data with both time-invariant covariates and time-variant covariates. These characteristics are accounted for data when estimates.

\section{Empirical Methodology}

The firm's survival time is modeled (Note 1) as a realization of a positive continuous random variable $T$. The probability that a firm goes out of operation within a time interval $[t, t+\Delta t]$, conditional on survival until time $t$, can be written as $\operatorname{Pr}(t \leq T<t+\Delta t \mid T \geq t)$, where the conditioning event that $T \geq t$ is just the event that the firm is still surviving at $t$.

The random variable $T$ has a cumulative distribution function $F(t)$, and for all points which $F(t)$ may be differentiated with probability density function $f(t)=F^{\prime}(t)$, that is:

$$
F(t)=\operatorname{Pr}(T \leq t)=\int_{0}^{t} f(s) d s
$$

The probability that a firm survives until time $t$ is given by the survivor function:

$$
S(t)=1-F(t)=\operatorname{Pr}(T \geq t)
$$

The hazard rate expresses the limit of the probability of failure in a short time interval $\Delta t$ conditional on surviving until $t$ and conditional on a vector of covariates $X_{i}$ (may include both time variant and time invariant variables). The hazard function $\lambda\left(t ; X_{i}\right)$ is given as:

$$
\lambda(t ; \mathrm{Xi})=\lim _{\Delta t \rightarrow 0} \frac{\operatorname{Pr}(\mathrm{t} \leq \mathrm{T}<\mathrm{t}+\Delta t \mid T \geq t, \mathrm{Xi})}{\Delta t}
$$


A proportional hazard model is given by

$$
\lambda\left(t, X_{i}\right)=\lambda_{o}(t) \exp \left(X_{i} \beta\right)
$$

The model is known as a proportional hazard model because the covariate and time dependency can be written in separable form, in which the baseline hazard $\lambda_{o}(t)$ is common to all, and the effect of covariate $X_{i}$ is a separable (proportional) one that either speeds up or slows down the process of ending the spell.

If a sample of $n$ completed spells is available, and each individual's spell is independent of the others, the likelihood function is the joint probability distribution of the sample as a function of parameters given by

$$
L(\theta)=\prod_{i=1}^{n} f\left(t_{i} \theta\right)
$$

where $\theta \equiv(\lambda, p)$ and $f\left(t_{i} \theta\right)$ is the parametric density of a duration of length $t$ implied by the assumed form for the hazard function.

According to Cox (1972 and 1975), the Cox proportional hazard method is used to estimate the slope coefficient in $\beta$ in the proportional hazard model, without specifying the pattern of the baseline hazard function $\lambda_{o}(t)$, by using the method of partial likelihood. The method of partial likelihood works in term of the time-ordering of events, whereas the maximum-likelihood concentrates on across firms (spells). This estimate is sometimes called a semi-parametric one because it attempts to synthesize the parametric and nonparametric approaches. The effect of the explanatory variables on survival is represented parametrically, but no specific form is assumed for the distribution of survival times.

Each sub-sample, its hazard $\lambda_{i}(t)$ is assumed to be a certain proportion of the baseline hazard, and this proportionality is a function of covariates:

$$
\left.\lambda\left(t, X_{i}\right)=\lambda_{o}(t) e^{\left(X_{i} \beta\right.}\right)
$$

Now, consider a data set of spells, $t_{1}, t_{2}, \ldots t_{n}$, arranged in order of length from shortest to longest. The conditional probability that Observation 1 fails at duration $t_{l}$, given that any of the $n$ observations could have failed at $t_{l}$, is

$$
\frac{\lambda\left(t_{1}, X_{1}\right)}{\sum_{i=1}^{n} \lambda\left(t_{1}, X_{i}\right)}=\frac{\lambda_{o}\left(t_{1}\right) \varphi\left(X_{1} \beta\right)}{\sum_{i=1}^{n} \lambda_{o}\left(t_{1}\right) \varphi\left(X_{i} \beta\right)}=\frac{\varphi\left(X_{1} \beta\right)}{\sum_{i=1}^{n} \varphi\left(X_{i} \beta\right)}
$$

The baseline hazard function $\lambda_{o}(t)$ is common to all sub-samples and is not influenced by any explanatory variables. The effect of covariate $X_{i}$ is a separable (proportional) one that either speeds up or slows down the process of ending the spell.

The same is true for observation ' $j$ ', the likelihood contribution is given by

$$
\frac{\varphi\left(X_{j} \beta\right)}{\sum_{k=j}^{n} \varphi\left(X_{k} \beta\right)}
$$

Thus, the log-likelihood function (Cox, 1972 and 1975) is given by

$$
\ln L(\beta)=\sum_{i=1}^{n}\left\{\ln \varphi\left(X_{i} \beta\right)-\ln \left[\sum_{j=i}^{n} \varphi\left(X_{j} \beta\right)\right]\right\}
$$

In the Cox proportional hazard regressions, there no assumptions are made about the shape of the baseline hazard rate. Estimates of the baseline survivor function in the Cox regression are empirical, without reference to any theoretical distribution.

The partial likelihood method can be applied to a random sample of spell with censoring observations, and it ties failure times as follows: Censoring can be handled in the partial likelihood estimation. A firm whose spell is censored between duration $t_{i}$ and $t_{i+1}$ is included in the summation in the denominator of the contribution to the partial likelihood of ordered and uncensored observations 1 through $i$ (the denominator of the contribution to partial likelihood corresponding to observations that fail before its censoring point). However, it is not included in the summation in the denominator of observations that fail after its censoring point. Hence, censored spells do not enter the numerator of a likelihood function term.

Applying this model requires that survival time is a continuous variable and that the firms can be ordered exactly with respect to their failure time, meaning that there are no tied survival times (a tie means that two or more 
observations exit at the same observed time). The data for this study is based on annual surveys, so the observed failure times are discrete variables (tied events occur in the survival data). The tie failures are solved as follows: Assuming that there are four firms in the risk pool in which Firms 1 and 2 both exit at time $t$. If we know that Firm 2 exits after Firm 1 (and assuming that then Firm 3 leaves and next to depart is Firm 4), the contribution to partial likelihood $(P L)$ would be

$$
P L(1)=\frac{\exp \left(X_{1} \beta\right)}{\exp \left(X_{1} \beta\right)+\exp \left(X_{2} \beta\right)+\exp \left(X_{3} \beta\right)+\exp \left(X_{4} \beta\right)}
$$

and

$$
P L(2)=\frac{\exp \left(X_{2} \beta\right)}{\exp \left(X_{2} \beta\right)+\exp \left(X_{3} \beta\right)+\exp \left(X_{4} \beta\right)}
$$

Whereas if Firm 2 had really exited first, followed by Firm 1, the contribution to partial likelihood would be

$$
P L(2)=\frac{\exp \left(X_{2} \beta\right)}{\exp \left(X_{1} \beta\right)+\exp \left(X_{2} \beta\right)+\exp \left(X_{3} \beta\right)+\exp \left(X_{4} \beta\right)}
$$

and

$$
P L(1)=\frac{\exp \left(X_{1} \beta\right)}{\exp \left(X_{1} \beta\right)+\exp \left(X_{3} \beta\right)+\exp \left(X_{4} \beta\right)}
$$

However, in practice, both Firms 1 and 2 exit at the same time, and we do not know which one exits first; thus, the only problem is caused by the second denominator. That is how to calculate the risk pool for the second firm and in which order to deal the two firms are at issue.

There are different ways to handle the tied failures. These include the Breslow method, the Efron method, the exact marginal method, and the exact partial method. At present, in this study, the Breslow and Efron methods are used to handle the tied failures in the calculation of the Cox partial likelihood as follows.

First method: The method of Breslow (1974): Because the order of firms' exit is not known, ties can be handled by using the same denominator for each of the tied exits. In other words, this method assumes that Firms 1 and 2 exit at time $t$, both use the same denominator as the sum of all the $\exp \left(X_{i} \beta\right): \exp \left(X_{1} \beta\right)+\exp \left(X_{2} \beta\right)+\exp \left(X_{3} \beta\right)+$ $\exp \left(X_{4} \beta\right)$ for all the tied exits. The calculation in this method is quick. However, the main disadvantage of this method is that in the case of many ties in the data, the method will not be very good because the risk pools have many observations.

Second method: The method of Efron (1977): Either Firm 1 or Firm 2 could exit first. The first exit takes the first risk pool as a sum of all the $\exp \left(X_{i} \beta\right)$ : $\exp \left(X_{1} \beta\right)+\exp \left(X_{2} \beta\right)+\exp \left(X_{3} \beta\right)+\exp \left(X_{4} \beta\right)$, and the second exit takes the denominator as $0.5 \exp \left(X_{1} \beta\right)+0.5 \exp \left(X_{2} \beta\right)+\exp \left(X_{3} \beta\right)+\exp \left(X_{4} \beta\right)$.

Similar weightings are used for cases of more than two ties. Efron's method is better than Breslow's because it is more accurate due to its consideration of the weight of exits.

\section{Statistic Descriptions}

\subsection{Dependent and Independent Variables}

There are two main dependent variables in the model. One is a status variable (Censorvar) to distinguish failure or survival. It is the dummy variable capturing the occurrence of the hazard. Censorvar $=1$ if the firm exits; otherwise, Censorvar $=0$. For instance, a firm $j$ exits at year $t(2003)$; its status variable, Censorvar $=0$ at the year 2000, 2001, and 2002, and Censorvar $=1$ at the year 2003. Or, a firm $k$ still survives at the end of the study period (2005); it is called a censored firm, and its status variable takes zero value for study years, Censorvar $=0$ in the years 2000, 2001, 2002, 2003, 2004, and 2005.

Another dependent variable is the duration variable (Duration), defined as the number of years the firm survives (firm's age). Besides, a unique identifier variable (ID) is also created for each firm (the ID is created following the firm's tax code), and each firm has its own ID. This is a sequence of positive integers. Using its unique ID, the firm can be tracked each year over the study period.

The firm's growth is represented by growth in employment and in assets and independent variables are as follows:

The previous growth in employment (LagGrowth): The firm's growth in employment is measured by the number of employees of the firm at year $t$ minus (-) the number of employees at year $t-1$, and then divided by the number 
of employees at year $t-1$. That is,

$$
\operatorname{Growth}(t)=[\operatorname{employment}(t)-\text { employment }(t-1)] / \text { employment }(t-1)
$$

Employment growth in the previous year $(t-1)$ is used to consider its effect on survival in the current year $(t)$.

The previous growth squared (LagGrowthSq): To allow for non-linearities, the previous growth squared is also used as an explanatory variable for considering the impact of the firm's growth on its survival. The previous growth is expected to be positive to survival, and the impact of growth on survival diminishes when growth is higher, meaning that the coefficient of LagGrowthSq is assumed to be positive to the hazard rate (or negative to the survival rate).

The previous growth in assets (LagAssetgrowth): This variable is included into the model to consider the effect of previous growth in assets on firm survival. Calculation for this variable is the same with the variable of growth in employment, simply replacing employment by assets. The firm's growth in assets is measured by the total assets of the firm at year $t$ minus (-) the total assets at year $t-1$, and then divided by the total assets at year $t$ -1 . That is,

$$
\operatorname{Asset} \operatorname{growth}(t)=[\operatorname{asset}(t)-\operatorname{asset}(t-1)] / \operatorname{asset}(t-1)
$$

Asset growth in the previous year $(t-1)$ is used to consider its effect on survival in the current year $(t)$.

The previous growth in assets squared (LagAssetgrowthSq): To allow for non-linearities, the previous growth in assets squared is also used as a covariate to consider the impact of the firm's growth on the firm's survival. It is thought that the coefficient of LagAssetgrowthSq is positive to the hazard rate to show that the effect of growth in assets on survival is decreasing.

In addition, there are other independent variables as follows:

The ownership type of firm: State-owned firms are denoted by the variable StateFirms $=1,0$ otherwise. Domestic private firms are denoted by DomesticFirms $=1,0$ otherwise. Foreign-owned firms are denoted by ForeignFirms $=1,0$ otherwise.

The economic sector of the firm in operation: Firms in the agricultural sector (rural, agricultural, and fishery industries) are denoted by the variable AgriSector $=1,0$ otherwise. Firms in the industrial sector (mining, construction, and manufacturing industries) are denoted by the variable InduSector $=1,0$ otherwise. Firms in the service sector (service industries) are denoted by ServSector $=1,0$ otherwise.

The initial founding conditions of the firm: Firm size (Lnsize) is the logarithm of the number of employees in the firm at the start-up year, if firms enter the market in or after 2000; or, for firms established prior to 2000, it is the logarithm of the number of employees in the firm at the year 2000 (the first year of the study period) divided by the firm's age until this year. Similarly, the firm's assets (Lnassets) is the logarithm of the total asset of the firm at the year 2000 divided by the firm's age until this year, for firms established prior to 2000; or, it is the logarithm of the total assets of the firm at its start-up year if the firm entered the market in or after 2000. The firm's initial liability (Initialdebt) is the firm's debt at the year 2000 (the first year of the study period) divided by the firm's age until the year 2000 for firms established prior to 2000; or, it is the firm's debt at the start-up year if the firm entered the market in or after 2000 (called initial debt). Capital-intensive (Capintensive) is the total capital per person employed by the firm at the year 2000 (the first year of the study period) divided by the firm's age until the year 2000 for firms established prior to 2000 and in 2000 ; or, it is the total capital per person employed by the firm at the start-up year, if the firm entered the market in or after 2000.

The firm's productivity: Sales to employees in year $t-1$ (LagSaleslabor) is defined by the firm's gross sales over total employees in year $t-1$. Earnings before tax (EBT) to employees in year $t-1$ (LagEBTlabor) is identified by dividing the firm's EBT by the total employees in year $t-1$.

The firm's financial ratios: Return to sales in year $t$-1 (LagROS) is calculated by dividing the earnings before tax by sales revenue in year $t-1$. Moreover, the return on assets in year $t-1$ (LagROA) is calculated by dividing the EBT by the total assets of the firm in year $t-1$. Leverage in year $t-1$ (LagLeverage) is calculated by dividing debt (including short -, medium - and long term debts) over the total assets in year $t-1$.

\subsection{Descriptive Statistics}

Table 1 presents the descriptive statistics of growth and other variables in the sample. The minimum growth in labour and assets is -1 (minus one), because when firms are out of the market, their labour and assets are 0 (zero). The maximum growth is 29.63 times for employment and 33.72 times for assets. The mean growth in employment and in assets is 0.113 times $(11.3 \%)$ and 0.209 times $(20.9 \%)$, respectively. The lag $(t-1)$ of growth 
is $26.2 \%$, and the lag $(t-1)$ of asset growth is $38.8 \%$. Of the three types of ownerships in the sample, the domestic private firms (DomesticFirms) achieve the highest ratio, with $68.1 \%$, and the state firms (StateFirms) are second, with $25.1 \%$. With respect to economic sectors, firms mainly operate in the service sector and in the industrial sector (mining, construction, and manufacturing industries), with $63.8 \%$ and $35.4 \%$, respectively. In terms of productivity represented by sales per employee in year $t-1$ and earnings before taxes per employee in year $t-1$, the mean productivity in the sample is positive, with 611 for sales per employee and 5.9 for the earnings before tax per employee. For ratios of profitability, the mean previous ROA (returns on assets) is positive but low (with $2.6 \%$ ), while the mean previous ROS (returns on sales) is negative (with $-5.3 \%$ ). The mean previous leverage ratio is $13.8 \%$.

Table 1. Summary of descriptive statistics

\begin{tabular}{llll}
\hline Variable & Obs & Mean & Std. Dev. \\
\hline Growth: Firm employment growth in year $t$ & 30,276 & 0.113 & 1.411 \\
LagGrowth: Firm employment growth in year $t-1$ & 22,329 & 0.262 & 1.503 \\
LagGrowthSq: Firm employment growth squared in year $t-1$ & 22,329 & 2.327 & 26.048 \\
Assetgrowth: Firm asset growth in year $t$ & 30,265 & 0.209 & 1.654 \\
LagAssetgrowth: Firm asset growth in year $t-1$ & 22,321 & 0.388 & 1.796 \\
LagAssetgrowthSq: Firm asset growth squared in year $t-1$ & 22,321 & 3.376 & 34.120 \\
StateFirms: State firms & 33,518 & 0.252 & 0.434 \\
DomesticFirms: Domestic private firms & 33,518 & 0.681 & 0.466 \\
ForeignFirms: Foreign firms & 33,518 & 0.067 & 0.251 \\
AgriSector: Agricultural sector & 33,518 & 0.007 & 0.085 \\
InduSector: Industrial sector & 33,518 & 0.354 & 0.478 \\
ServSector: Service sector & 33,518 & 0.638 & 0.481 \\
Lnsize: Ln(Firm employment size) & 33,499 & 2.791 & 1.575 \\
Lnassets: Ln(Firm asset size) & 33,516 & 7.574 & 1.950 \\
Initialdebt: Initial debt & 33,518 & 8148.30 & 29330.11 \\
Capintensive: Capital intensity & 33,518 & 64.83 & 224.61 \\
LagSaleslabor: Sales per employee in $t-1$ & 25,556 & 611.50 & 1329.11 \\
LagEBTlabor: Earnings before tax per employee in year $t-1$ & 25,556 & 5.919 & 39.628 \\
LagROS: Returns on sales in year $t-1$ & 25,556 & -0.053 & 0.696 \\
LagROA: Returns on assets in year $t-1$ & 25,556 & 0.026 & 0.180 \\
LagLeverage: Leverage in year $t-1$ & 30,518 & 0.138 & 0.298 \\
\hline
\end{tabular}

\section{Empirical Results}

With the sample of 7,962 firms, the hazard models used to estimate the effect of firm growth and other determinants on the survival/exit rates in this paper is the semi-parametric model - the Cox proportional hazard model. In the models presented in this paper, the reference groups are StateFirms (state firms), which represent the ownership type of firm, and AgriSector (AgriSector includes rural, agricultural, fishery industries), which represent firms in the economic sector.

In these hazard models, a coefficient greater than zero $(>0)$ implies a positive impact on the hazard (failure) rate or a negative effect on the survival rate, all other things being equal. In contrast, a coefficient less than zero $(<0)$ refers to a negative effect on the hazard rate or a positive influence on the survival rate, all other things being equal.

The method of the Cox partial likelihood estimation in analyzing the effect of growth on firm survival does not need to specify any assumptions about the shape of the baseline hazard function. Furthermore, this approach can be applied to a random sample of spell with censoring observations and it ties failure times.

The results of the Cox proportional hazard estimated model with the Efron and Breslow methods for treating ties are given in Table 2 and 3, respectively. Both the Efron and Breslow methods used is to compare their results each other. The results of the Efron and Breslow methods are almost identical. There are three specifications (1, 2 and 3 ) in each table (Table 2 and 3); subsequent specification is equal to previous specification added to one more group of independent variables. In the model's analysis of the coefficients, in order to find out factors that influence hazard and survival rates, the result of the Efron method is used because it may provide more accurate results due to its higher log likelihood. We show the results of using the Efron method on the sample of 7,962 
firms in Table 2 and observe that the results of coefficients among the specifications (1,2 and 3$)$ are unchanged their signs when adding more explanatory variables in various specifications.

\subsection{The Effect of Growth on Firm Survival}

In order to express the relationship between growth in year $t-1$ and survival rate in year $t$, some covariates of firm growth are included in the empirical analysis: the firm growth in employment in year $t-1$ and the firm growth in terms of total assets in year $t-1$. To check the non-linearities in the associations between firm growth and hazard rate (or survival rate), these two growth variables are squared. Table 2 demonstrates the effect of growth on firm survival.

The variable of the growth in employment (LagGrowth): The estimated coefficient of LagGrowth in the Cox regressions is negative and statistically significant. This result indicates that firm growth in year $t-1$ has a positive impact on firm survival (or a negative effect on the hazard rate of exit) in year $t$, meaning that firms which grow more can expect to survive longer. As we hypothesized, this result is in accordance with Jovanovic's (1982) model and previous empirical study results. Firms with higher growth rates may be able to accumulate the necessary resources to provide the expansion and needed to become larger firms (Mata et al., 1995). They may also have longer lifetimes. Conversely, firms with no growth rate or a negative growth rate may gradually become smaller and weaker, and eventually they have to halt business and escape from the market. Furthermore, higher growth may come from the firm having viably new projects, business plans, or products that can meet the demand of customers and help to gain more profitability. Thus, firms with a higher growth rate may have a higher likelihood of survival. Audretsch (1995) states that surviving firms have a high growth rate, and he shows that firms having a positive growth rate are able to survive longer, as they are successful in adjusting and producing viable products to meet the demand of the market. Additionally, higher growth is a result of the firm gaining more productivity and more profitability (i.e. higher growth comes from higher productivity and higher profitability). This helps the firm to resist bankruptcy. A similar study in developing countries (six countries in Africa) by Mead and Liedholm (1998) asserts that small and medium-sized firms which increase their number of workers are more likely to survive than those which maintain the same size since start-up. This demonstrates that small and medium firms which grow are more efficient and, as a result, are more likely to stay in the market. A higher growth rate may help the firm in doing business with other partners and clients since, according to Mc Pherson (1995), the firm with a higher growth may, in some sense, be thought of as the firm of the success and superior and it has received its true efficiency level. Thus, this may increase the firm's ability to attain alliance partners, consumer goodwill, and trust. As pointed out by Almus (2004), the firm's growth positively influences its performance and survival because growth is considered a sign of overcoming the firm's internal and external shocks (such as lower demand conditions, an increase in competition, a rise in input prices, or the leaving or retirement of an important manager).

Hence, growth rate can be applied to measure the firm's performance. Firms with a higher growth rate may have better performance and better prospects of survival. Conversely, inferior performance in a firm may imply no or negative growth and, subsequently, a lower probability of the survival. The result of this empirical study is consistent with Jovanovic (1982) and Pakes and Ericson's (1998) models. That is, firm growth is proxy to the firm's process of learning. The firm that maintains growth after entry is more likely to survive longer because post-entry growth is a result of learning to operate more efficiently.

From the specification (3) in table 2, we can predict the effect of growth on the firm's survival/failure in the following manner: we can calculate the hazard ratio $\left(e^{\beta}\right)$ for the variable of growth. The coefficient of LagGrowth is -0.0655 ; the hazard ratio of growth is $\mathrm{e}^{-0.0655} \approx 0.9366$. A useful statistic is obtained if the hazard ratio is subtracted by 1 and multiplied by 100 . This means that the percentage change in the hazard of failure is estimated for each one-unit increase in the covariate; for example a percentage point increase in previous employment growth (variable of LagGrowth) induces a decrease of $6.34 \%$ in the hazard of exit, holding constant for other covariates.

The squared previous growth in employment (LagGrowthSq): The effect of growth may be non-linear, so a quadratic term is included to allow for non-linearity. The variable of firm growth in employment in year $t-1$ is squared. The LagGrowthSq's coefficient is statistically significant, indicating that the relationship between previous growth in employment and the risk of failure (or the chance of survival) is a non-linearity. Moreover, the positive coefficient confirms that the effect level of growth on the hazard rate is negative and at an increase rate. In other words, the coefficient of previous growth is negative, but the coefficient of the squared previous growth is positive, suggesting that the slope of the curve is negative and increasing (the negative slope tends to be less steep as growth increases). The growth positively influences survival, but the advantage of higher growth 
declines with increasing growth in employment (if the growth is higher, then its effect on the survival is decreasing).

This empirical result is consistent with some theories and models studied previously. First of all, the result is in line with Penrose's (1959) theory of firm growth. That is, there is a maximum growth rate for the firm, and when the firm achieves to a maximum point at which its growth rate tends to diminish and its absolute size is going on increasing because there is a limit provided by the managerial capacity and productive opportunity. Below the maximum growth rate, the firm's capacity of management is released for new plans at a faster rate than such plans are generated. Above this maximum rate of growth, the existing managerial capacity is exceeded, and new managerial services are needed. As a result, costs increase. Hence, productive opportunity and managerial capacity are limited to the extent to which the firm realizes that high growth will not be efficient, or to the extent that it does not see opportunities for expansion. The result is in accordance with the life cycle theory of the firm presented by Mueller (1972). That is, in the early stages of the firm's development, there is quick growth because all profits gained and all capital consumption allowances are reinvested by the stockholders and even additional outside capital is raised to invest in this stage as well taking advantage of profitable opportunities from new ideas and new market is for this stage. Thus, the firm expands to reach its maximum size. After that, further expansion has limits, such as the loss of information and control, which reduces the firm's ability to introduce new products and techniques, even if there are no increase in the costs of producing the present product lines with existing techniques. As a result, the firm's profitability is effectively lower and/or could lead to a collapse. This means that managerial diseconomies of scale exist in the life cycle theory of the firm. The empirical result is in line with Spence's (1979) model, which asserts that, in the growing phase of the evolutionary process, firms able to expand quickly, and/or firms that enter early the market, can make a pre-emptive investment in their strategic behaviour so that they can reach the optimal penetration of the market (gain dominance in the market) because in the mature phase opportunities for changing the firm's market position are very limited; hence, firms will grow at lower rate. This result is also complimentary to Nelson and Winter's (1978) model, which states that the growth rate decreases with firm size and an average growth rate increases and then flattens out, or decreases, with firm size. After reaching a certain size, as firms become large ones and set higher target mark-ups, they restrain their growth to prevent a decrease in price.

In the specification (3) of table 2, the coefficient of LagGrowth is -0.0655 , and the coefficient of LagGrowthSq is 0.0042 . Assuming that the other covariates are constant, the quadratic function:

$$
\text { 0.0042(LagGrowth) })^{2}+(-0.0655) \text { LagGrowth }
$$

has minimum at $-(-0.0655) / 2(0.0042)=7.80$, at which point the function changes direction. Up to a growth of 7.80 , the relative hazard rate falls; after that the hazard rate goes up at an increasing rate. A turning point at 7.80 is estimated within the range of LagGrowth $[-1,29.63]$ in Table 1.

The turning point here is relatively high because, as discussed in descriptive statistics, Vietnam is a new emerging market and labour abundant country where there are many opportunities for firms to grow quickly. Additionally, firm size in Vietnam is generally small, and small firms experience higher growth rates than larger ones. In recent years, firms in Vietnam have appeared in industries in which it is easy to increase employment, such as the garment, textile, restaurant, hotel, and tourism industries. Moreover, due to a new market, many investment projects and new ventures are in the installation stage, and when they are finished with this stage, they will be taken into operation. The transition from installation to operation creates remarkable growth because several employees are typically recruited for the firm at the beginning of the operation phase.

Vietnamese firms have experienced high growth in recent years, and if firms have growth rates up to 7.80 , then their failure rate declines. However, if firms have an employment growth of above 7.80, then their hazard rate increases because of one or more of the reasons discussed previously. To be more specific: first, firms with too high of a growth rate may not able to control their performance and growth (because of managerial capacity, avoiding down prices, diseconomies of scale, etc), so they may be considered very risky ventures which are easily liable to bankruptcy. Second, in Vietnam's situation, state firms are in the process of governmental reform. That is, some firms are integrated into each other, and they have high growth, thus becoming larger. This, however, generates difficulties (such as human resource, management, strategies, and so on) for management board of the existing firms, thus badly affecting their performance and efficiency. At present, there are some cases wherein state firms are not efficient; however, the government does not want to privatize or sell them to the public for certain reasons; hence, they are merged into other state firms. These inefficient firms are a heavy burden for existing state firms and a bad influence on the performance of existing state firms. Finally, some firms are established to do one or some business ventures or business plans for some years, after which they will 
terminate business and escape the market. As a result, they have very high growth rates and short lifetimes.

This result may prove that growth in employment has a good and necessary impact on the firm's survival chances. However, the firm can increase its growth rate up to a certain point which can improve survival rate; after that, if the firm continues increasing its growth rate, then the effect of growth on survival likelihood decreases. Hence, to maintain the positive effect of growth on survival over time (meaning that the advantages of a higher growth increase with the rising growth in employment), it is necessary to pay attention to the quality of growth in employment. That is, growth should be combined with other factors (productivity, financial ratios, and so on) in order to generate significantly positive impacts on the survival. In addition to growth in employment, there are also other covariates which have a significant impact on survival and failure rates.

The previous growth in assets (LagAssetgrowth): Beside the firm growth in employment, another aspect of growth may be measured by an increase in total assets. The variables of the previous growth in assets are included in the model in order to clarify another aspect of the effect of firm growth on the survival rate. When adding variables of firm growth in assets in Specifications 2 and 3 in table 2, the results of other variables are almost unchanged, particularly as concerns the sign of coefficients. Like the variable of previous growth in employment, this variable's coefficient is negative and statistically significant. Its negative significance is as we expected and implies that there is a positive relationship between the previous growth in assets and the likelihood of survival (or a negative association between the previous growth in assets and the hazard rate of failure).

From the specification (3) in Table 2, we can calculate the hazard ratio $\left(e^{\beta}\right)$ for the variable of LagAssetgrowth. The coefficient of the LagAssetgrowth is -0.1331 ; the hazard ratio of Assetgrowth is $\mathrm{e}^{-0.1331} \approx 0.8754$. This means that a percentage point rise in asset growth in year $t-1$ (variable of LagAssetgrowth) reduces the hazard of failure by $12.46 \%$. Therefore, the effect of previous asset growth on firm survival is stronger than that of employment growth on firm survival.

The previous growth in assets squared (LagAssetgrowthSq): To consider whether non-linearity exists in the relationship between growth in assets and the hazard rate, the previous growth in assets is squared. The coefficient of the LagAssetgrowthSq is positive and statistically significant; it is the same sign with the coefficient of the squared growth in employment, demonstrating that non-linearity exists in this relationship and that the advantages of higher growth in the previous year decrease when increasing the previous growth in assets (because the effect of the growth in assets on the hazard rate is negative and at an increasing rate). In other words, the higher the growth is, the lower the hazard rate is.

The coefficient of LagAssetgrowth is negative and the coefficient of LagAssetgrowthSq is positive, because the negative slope tends to become less steep as growth rises. The previous growth in assets positively influences survival; however, up to a certain level, if the firm increases the previous growth in assets, the effect of the previous growth on survival declines. The certain point of previous asset growth is identified as similar to the quadratic function for employment growth, in specification (3) of Table 2; the coefficient of LagAssetgrowth is -0.1331 , and the coefficient of LagAssetgrowthSq is 0.0043 . Assuming that other independent variables are constant, the quadratic function:

$$
\text { 0.0043(LagAssetgrowth })^{2}+(-0.1331) \text { LagAssetgrowth }
$$

has a minimum at $-(-0.1331) / 2(0.0043)=15.48$ at which point the function changes direction. Up to growth of 15.48, the relative hazard rate falls, and after that the hazard rate goes up at an increasing rate. A turning point at 15.48 is estimated within the range of LagAssetgrowth [-1, 33.72] in Table 1.

The turning point in asset growth (15.48) is higher than the one in employment growth (7.8) because the mean growth in assets and the regression coefficient of asset growth are higher than those in employment. This is possible that the demand of assets for firms in Vietnam to survive is high in this period.

In summary, firm growth (both in employment and in assets) in year $t-1$ is important to firm survival and has a positive impact on the probability of firm survival in year $t$. Firms with higher previous growth may avoid failure from the market and increase their probability of survival in the current year. Additionally, non-linearities are present in the association between previous growth and the risk of exit (or the survival rate). Moreover, as the previous growth rate increases, the effect level of previous growth on the hazard rate is negative and at an increasing rate, meaning that the advantages of higher growth decline with the rise in growth. This demonstrates that, in order to stay in business for a longer time, firms need to maintain not only growth, but also efficiency, as well as productivity, the ability to efficiently use assets, and so on.

Therefore, in addition to the variables of previous growth on survival and hazard exit rates, there are other determinants that may also affect firm survival. These other factors are analysed in the next sections. 
Table 2. Cox proportional hazard regressions for firms in Vietnam with the Efron method for treating ties

\begin{tabular}{|c|c|c|c|}
\hline \multirow[t]{2}{*}{ Variables } & \multicolumn{3}{|c|}{ Parameter estimates } \\
\hline & $(1)$ & $(2)$ & (3) \\
\hline \multirow[t]{2}{*}{ DomesticFirms: Domestic private firms } & $-0.5109 * * *$ & $-0.4874 * * *$ & $-0.5224 * * *$ \\
\hline & $(0.0463)$ & $(0.0465)$ & $(0.0468)$ \\
\hline \multirow[t]{2}{*}{ ForeignFirms: Foreign firms } & $-1.0488 * * *$ & $-1.0200 * * *$ & $-1.0560 * * *$ \\
\hline & $(0.1201)$ & $(0.1203)$ & $(0.1202)$ \\
\hline \multirow[t]{2}{*}{ InduSector: Industrial sector } & -0.3101 & $-0.3300^{*}$ & $-0.3250^{*}$ \\
\hline & $(0.2096)$ & $(0.2006)$ & $(0.2007)$ \\
\hline \multirow[t]{2}{*}{ ServSector: Service sector } & -0.3108 & -0.3241 & -0.3206 \\
\hline & $(0.2094)$ & $(0.2094)$ & $(0.2094)$ \\
\hline \multirow[t]{2}{*}{ Lnsize: Ln(Firm employment size) } & -0.0207 & -0.0107 & -0.0186 \\
\hline & $(0.0240)$ & $(0.0240)$ & $(0.0241)$ \\
\hline \multirow[t]{2}{*}{ Lnassets: Ln(Firm asset size) } & $-0.0358 *$ & $-0.0423 * *$ & $-0.0503 * * *$ \\
\hline & $(0.0196)$ & $(0.0197)$ & $(0.0197)$ \\
\hline \multirow[t]{2}{*}{ Initialdebt: Initial debt } & $-3.06 \mathrm{e}-06^{* *}$ & $-2.39 \mathrm{e}-06^{*}$ & $-2.38 \mathrm{e}-06^{*}$ \\
\hline & $(1.32 \mathrm{e}-06)$ & $(1.30 \mathrm{e}-06)$ & $(1.31 \mathrm{e}-06)$ \\
\hline \multirow[t]{2}{*}{ Capintensive: Capital intensity } & $3.61 \mathrm{e}-05$ & 0.0001 & 0.0001 \\
\hline & $(0.0001)$ & $(0.0001)$ & $(0.0001)$ \\
\hline \multirow[t]{2}{*}{ LagSaleslabor: Sales per employee in $t-1$} & $-1.45 \mathrm{e}-06$ & $7.02 \mathrm{e}-06$ & $5.03 \mathrm{e}-06$ \\
\hline & $(1.66 \mathrm{e}-05)$ & $(1.65 \mathrm{e}-05)$ & $(1.65 \mathrm{e}-05)$ \\
\hline \multirow[t]{2}{*}{ LagEBTlabor: Earnings before tax per employee in year $t-1$} & $-0.0034 * * *$ & $-0.0034 * * *$ & $-0.0020 * * *$ \\
\hline & $(0.0006)$ & $(0.0006)$ & $(0.0006)$ \\
\hline \multirow[t]{2}{*}{ LagGrowth: Firm employment growth in year $t-1$} & $-0.0923 * * *$ & $-0.0564 * *$ & $-0.0655^{* * *}$ \\
\hline & $(0.0274)$ & $(0.0277)$ & $(0.0278)$ \\
\hline \multirow[t]{2}{*}{ LagGrowthSq: Firm employment growth squared in year $t-1$} & $0.0049 * * *$ & $0.0039 * * *$ & $0.0042 * * *$ \\
\hline & $(0.0013)$ & $(0.0013)$ & $(0.0013)$ \\
\hline \multirow[t]{2}{*}{ LagAssetgrowth: Firm asset growth in year $t-1$} & & $-0.1455^{* * *}$ & $-0.1331 * * *$ \\
\hline & & $(0.0265)$ & $(0.0263)$ \\
\hline \multirow[t]{2}{*}{ LagAssetgrowthSq: Firm asset growth squared in year $t-1$} & & $0.0051^{* * *}$ & $0.0043^{* * *}$ \\
\hline & & $(0.0011)$ & $(0.0010)$ \\
\hline \multirow[t]{2}{*}{ LagROS: Returns on sales in year $t-1$} & & & -0.0259 \\
\hline & & & $(0.0286)$ \\
\hline \multirow[t]{2}{*}{ LagROA: Returns on assets in year $t-1$} & & & $-0.4525 * * *$ \\
\hline & & & $(0.0891)$ \\
\hline \multirow[t]{2}{*}{ LagLeverage: Leverage in year $t-1$} & & & $0.2150^{* * *}$ \\
\hline & & & $(0.0559)$ \\
\hline Log Likelihood & $-18,674.0$ & $-18,655.7$ & $-18,581.0$ \\
\hline LR (p value) & 0.0000 & 0.0000 & 0.0000 \\
\hline Number of firms $(\mathrm{N})$ & 6,707 & 6,707 & 6,705 \\
\hline Observations & 22,300 & 22,288 & 22,261 \\
\hline
\end{tabular}

Notes: The reference groups for dummies are StateFirms and AgriSector. Std. Error values are in parentheses. $* * *$ is significant at $1 \%$, ** is significant at $5 \%$ and $*$ is significant at $10 \%$. 
Table 3. Cox proportional hazard regressions for firms in Vietnam with the Breslow method for treating ties

\begin{tabular}{|c|c|c|c|}
\hline \multirow[t]{2}{*}{ Variables } & \multicolumn{3}{|c|}{ Parameter estimates } \\
\hline & (1) & $(2)$ & (3) \\
\hline \multirow[t]{2}{*}{ DomesticFirms: Domestic private firms } & $-0.4753 * * *$ & $-0.4534 * * *$ & $-0.4859 * * *$ \\
\hline & $(0.0463)$ & $(0.0465)$ & $(0.0469)$ \\
\hline \multirow[t]{2}{*}{ ForeignFirms: Foreign firms } & $-0.9959 * * *$ & $-0.9680 * * *$ & $-1.0029 * * *$ \\
\hline & $(0.1199)$ & $(0.1201)$ & $(0.1201)$ \\
\hline \multirow[t]{2}{*}{ InduSector: Industrial sector } & -0.3027 & -0.3209 & -0.3150 \\
\hline & $(0.2096)$ & $(0.2096)$ & $(0.2097)$ \\
\hline \multirow[t]{2}{*}{ ServSector: Service sector } & -0.3025 & -0.3144 & -0.3093 \\
\hline & $(0.2093)$ & $(0.2093)$ & $(0.2094)$ \\
\hline \multirow[t]{2}{*}{ Lnsize: Ln(Firm employment size) } & -0.0199 & -0.0107 & -0.0176 \\
\hline & $(0.0239)$ & $(0.0239)$ & $(0.0241)$ \\
\hline \multirow[t]{2}{*}{ Lnassets: Ln(Firm asset size) } & $-0.0335^{*}$ & $-0.0396 * *$ & $-0.0461 * * *$ \\
\hline & $(0.0195)$ & $(0.0196)$ & $(0.0196)$ \\
\hline \multirow[t]{2}{*}{ Initialdebt: Initial debt } & $-2.91 e-06 * *$ & $-2.27 \mathrm{e}-06^{*}$ & $-2.33 \mathrm{e}-06^{*}$ \\
\hline & $(1.31 \mathrm{e}-06)$ & $(1.29 \mathrm{e}-06)$ & $(1.31 \mathrm{e}-06)$ \\
\hline \multirow[t]{2}{*}{ Capintensive: Capital intensity } & $3.51 \mathrm{e}-05$ & 0.0001 & 0.0001 \\
\hline & $(0.0001)$ & $(0.0001)$ & $(0.0001)$ \\
\hline \multirow[t]{2}{*}{ LagSaleslabor: Sales per employee in $t-1$} & $-3.49 \mathrm{e}-07$ & $7.29 \mathrm{e}-06$ & $5.27 \mathrm{e}-06$ \\
\hline & $(1.64 \mathrm{e}-05)$ & $(1.64 \mathrm{e}-05)$ & $(1.64 \mathrm{e}-05)$ \\
\hline \multirow[t]{2}{*}{ LagEBTlabor: Earnings before tax per employee in year $t-1$} & $-0.0031 * * *$ & $-0.0031 * * *$ & $-0.0018 * * *$ \\
\hline & $(0.0006)$ & $(0.0006)$ & $(0.0006)$ \\
\hline \multirow[t]{2}{*}{ LagGrowth: Firm employment growth in year $t-1$} & $-0.0837 * * *$ & $-0.0507 * *$ & $-0.0572 * *$ \\
\hline & $(0.0271)$ & $(0.0275)$ & $(0.0276)$ \\
\hline \multirow{2}{*}{ LagGrowthSq: Firm employment growth squared in year $t-1$} & $0.0044 * * *$ & $0.0034 * * *$ & $0.0036^{* * *}$ \\
\hline & $(0.0013)$ & $(0.0013)$ & $(0.0013)$ \\
\hline \multirow[t]{2}{*}{ LagAssetgrowth: Firm asset growth in year $t-1$} & & $-0.1340 * * *$ & $-0.1213 * * *$ \\
\hline & & $(0.0263)$ & $(0.0261)$ \\
\hline \multirow[t]{2}{*}{ LagAssetgrowthSq: Firm asset growth squared in year $t-1$} & & $0.0047^{* * *}$ & $0.0038 * * *$ \\
\hline & & $(0.0011)$ & $(0.0010)$ \\
\hline \multirow[t]{2}{*}{ LagROS: Returns on sales in year $t-1$} & & & -0.0262 \\
\hline & & & $(0.0281)$ \\
\hline \multirow[t]{2}{*}{ LagROA: Returns on assets in year $t-1$} & & & $-0.4113 * * *$ \\
\hline & & & $(0.0894)$ \\
\hline \multirow[t]{2}{*}{ LagLeverage: Leverage in year $t-1$} & & & $0.1787 * * *$ \\
\hline & & & $(0.0543)$ \\
\hline Log Likelihood & $-18,864.9$ & $-18,849.1$ & $-18,777.7$ \\
\hline LR (p value) & 0.0000 & 0.0000 & 0.0000 \\
\hline Number of firms $(\mathrm{N})$ & 6,707 & 6,707 & 6,705 \\
\hline Observations & 22,300 & 22,288 & 22,261 \\
\hline
\end{tabular}

Notes: The reference groups for dummies are StateFirms and AgriSector. Std. Error values are in parentheses. $* * *$ is significant at $1 \%$, $* *$ is significant at $5 \%$ and $*$ is significant at $10 \%$.

\subsection{Other Determinants on Firm Survival}

The DomesticFirms' coefficient is negative and statistically significant. This means that, compared to state firms, the more firms entry under the forms of ownerships of domestic private firms do, the lower hazard exit rates are (the higher survival rates are).

The coefficient of ForeignFirms has appeared as statistically significant and negative when considering the effects of other covariates in the model. There is a negative relationship between the hazard rate and the type of firm owned by foreigners. More firms entering the market under this form help the Vietnamese firms to be more likely to survive, when compared to the state firms.

The initial asset size (Lnassets): Beside firm size by employment, firm initial size is also measured by initial assets. This variable is included into the model in order to consider how the firm size by assets impacts the firm's survival. The result shows that there is a negative and statistically significant association between initial assets 
and the hazard rate, implying that the firm with greater initial assets is more likely to survive. The initial debt (Initialdebt): Although the magnitude of the coefficient is small, a negative and statistically significant coefficient may suggest that the more initial debt firms possess, the more likelihood of survival they have.

The variable of earnings before taxes over employees in the previous year (LagEBTlabor) can show the firm's productivity in year $t-1$ in order to influence the hazard rate in year $t$ (or the probability of survival in year $t$ ). The coefficient of this variable in the model is negative and statistically significant, meaning that firms with higher productivity in year $t-1$ are more likely to survive in year $t$.

The returns on assets in year $t-1$ (LagROA) appears to be a negative and statistically significant coefficient, implying that the return on assets in year $t-1$ has a positive impact on the probability of survival in year $t$.

The leverage in year $t-1$ (LagLeverage) is measured by total debt over total assets in year $t-1$ corresponding to each year (time-variant covariates) in order to show the ratio of the firm's assets financed by debt. A higher ratio means that the firm's debt is higher. The coefficient is positive and statistically significant, suggesting that leverage in year $t-1$ has a negative effect on the probability of survival in year $t$. The sign of this variable (positive on the hazard rate) is opposite to the sign of the initial debt variable (negative on the hazard rate), demonstrating that, although higher initial debt may increase the likelihood of survival because it shows the ability of accessing external financial resources to support initial difficulties in operation; nevertheless, higher debt (when the firm is in stable operation) may decrease the firm's chances of survival, since high leverage leads to high risk. Thus, lenders typically refuse to provide money to firms having high degrees of leverage.

\section{Conclusion and Policy Implications}

\subsection{Conclusion}

From the regression results of the Cox proportional hazard model with the dataset of 7,962 firms in Vietnam, we find that the effect of growth and other determinants on the survival of Vietnamese firms can be summarized as follows:

The effect of previous growth (both in terms of employment and of assets) is important to firm survival. Firms with higher previous growth may increase the likelihood of survival, and non-linearities exist in this relationship. The effect of previous growth on the hazard rate is negative and at an increasing rate, implying that the effect of growth on firm survival decreases as growth increases.

Characteristics of domestic private firms and foreign firms have positive impacts on survival, when compared with the state firms. In other words, the presence of domestic private and foreign firms increases survival probability for firms in Vietnam. Among initial founding conditions, the firm size in assets and initial debt have positive relationships with firm survival. With respect to variables of firm productivity, earning before taxes over labour in year $t-1$ is important and has a positive impact on firm survival in year $t$. Related to the profit variables, the return on assets in year $t-1$ is positive and significant to firm survival in year $t$. The leverage in year $t-1$ is found to have a negative impact on the probability of survival in year $t$ for firms in Vietnam.

\subsection{Policy Implications}

The probability of firm survival is based not only on its ability, but also on the government policy constraints of the country in which the firm is in business. The change in governmental policies may negatively or positively influence the survival rate (or the hazard rate). After analyzing the effects of growth and other determinants to firm survival, we can recommend some public policies to improve the survival chances for Vietnamese firms as follows:

Growth, particularly in the initial stages, will lead the firm to avoid failure from the market. Hence, assistance programmes for firms after start-up (for new firms) should be considered in order to help these firms grow.

There are different survival rates among different types of firms. When considering the effects of the covariates of efficiency, foreign and domestic private firms display higher probability of survival, in comparison to state firms. Hence, in order to improve the survival probability of firms in Vietnam, some policy implications are: To encourage the domestic private firms to set up and attract more foreign direct investment into Vietnam; To decrease the support, preference, and privileges of state firms, as compared to foreign and domestic private firms, in order to create a more equal business environment among different types of firms in the economy; To quickly push the process of privatizing state firms so that domestic private and foreign owners can enter these state firms; To allow domestic private and foreign firms to access industries which state firms currently monopolize.

The initial assets size and initial debt have positive impacts on survival, so government policies should be issued 
to promote the financial market in creating and developing opportunities for new firms to acquire access to initial finances. Initial support or initial loan programmes for new entrants should be suggested in order to support new firms.

Owners and entrepreneurs should pay attention to augmenting productivity and profitability and to controlling their firm's level of leverage in order to increase the probability of survival.

\section{Acknowledgements}

I sincerely thank Prof. Tim Barmby and Prof. Hans K. Hvide for useful guidance. I would also like to thank participatants' comments at VEAM 2011. All remaining errors are my sole responsibility.

\section{References}

Almus, M. (2004). The Shadow of Death - An Empirical Analysis of the Pre-Exit Performance of New German Firms. Small Business Economics, 23, 189-201. http://dx.doi.org/10.1023/B:SBEJ.0000032033.00519.00

Audretsch, D. B. (1995a). Innovation and Industry Evolution. Massachusetts Institute of Technology.

Audretsch, D. B. (1995b). Innovation, growth and survival. International Journal of Industrial Organization, 13, 441-457. http://dx.doi.org/10.1016/0167-7187(95)00499-8

Barmby, T. (2001). Analysis of Duration Data. unpublished notes for Postgraduate Research Workshop, Department of Economics, University of Aberdeen, UK.

Breslow, N. (1974). Covariance Analysis of Censored Survival Data. Biometrics, 30, 89-99. http://dx.doi.org/10.2307/2529620

Cox, D. R. (1972). Regression Models and Life-Tables. Journal of the Royal Statistical Society, Series B (Methodological), 34, 187-220.

Cox, D. R. (1975). Partial Likelihood. Biometrika, 62, 269-276. http://dx.doi.org/10.1093/biomet/62.2.269

Dunne, T., Roberts, M. J., \& Samuelson, L. (1989). The Growth and Failure of U.S. Manufacturing Plants. The Quarterly Journal of Economics, 104, 671-698. http://dx.doi.org/10.2307/2937862

Efron, B. (1977). The Efficiency of Cox's Likelihood Function for Censored Data. Journal of the American Statistical Association, 72, 557-567. http://dx.doi.org/10.1080/01621459.1977.10480613

Evan, D. S. (1987a). Test of Alternative Theories of Firm Growth. The Journal of Political Economy, 95, 657-674. http://dx.doi.org/10.1086/261480

Evan, D. S. (1987b). The Relationship Between Firm Growth, Size, and Age: Estimates for 100 Manufacturing Industries. The Journal of Industrial Economics, 35, 567-581. http://dx.doi.org/10.2307/2098588

Fotopulos, G., \& Louri, H. (2000a). Determinants of Hazard Confronting New Entry: Does Financial Structure Matter? Review of Industrial Organization, 17, 285-300. http://dx.doi.org/10.1023/A:1007862922531

Fotopulos, G., \& Louri, H. (2000b). Location and Survival of New Entry. Small Business Economics, 14, 311-321. http://dx.doi.org/10.1023/A:1008180522759

Holmes, P., Hunt, A., \& Stone, I. (2010). An Analysis of New Firm Survival Using a Hazrd Funaction'. Applied Economics, 42, 185-195. http://dx.doi.org/10.1080/00036840701579234

Jenkin, S. P. (1995). Easy Estimation Methods for Discrete-Time Duration Models. Oxford Bulletin of Economics and Statistics, 57, 129-137. http://dx.doi.org/10.1111/j.1468-0084.1995.tb00031.x

Jenkin, S. P. (2004). Survival Analysis. Unpublished manuscript, Institute for Social and Economic Research, University of Essex, Colchester, UK. Retrieved May 2010 from http://www.iser.essex.ac.uk/teaching/degree/stephenj/ec968/pdfs/ec968lnotesv6.pdf

Jovanovic, B. (1982). Selection and the Evolution of Industry. Econometrica, 50, 649-670. http://dx.doi.org/10.2307/1912606

Kiefer, N. M. (1988). Economic Duration Data and Hazard Functions. Journal of Economic Literature, XXVI, 646-679.

Lancaster, T. (1979). Econometrics Methods for the Duration of Unemployment. Econometrica, 47, 939-956. http://dx.doi.org/10.2307/1914140

Lancaster, T. (1990). The Econometric Analysis of Transition Data. Cambridge University Press.

Mata, J., \& Portugal, P. (1994). Life duration of new firms. The Journal of Industrial Economics, 42, 227-245. 
http://dx.doi.org/10.2307/2950567

Mata, J., \& Portugal, P. (2002). The Survival of New Domestic and Foreign-Owned Firms. Strategic Management Journal, 23, 323-343. http://dx.doi.org/10.1002/smj.217

Mata, J., Portugal, P., \& Guimaraes, P. (1995). The Survival of New Plants: Start-up Conditions and Post-entry Evolution. International Journal of Industrial Organization, 13, 459-481. http://dx.doi.org/10.1016/0167-7187(95)00500-5

McPherson, M. A. (1995). The hazards of small firms in Southern Africa. The Journal of Development Studies, 32, 31. http://dx.doi.org/10.1080/00220389508422400

Mead, D. C., \& Liedholm, C. (1998). The Dynamics of Micro and Small Enterprises in Developing Countries. World Development, 26, 61-74. http://dx.doi.org/10.1016/S0305-750X(97)10010-9

Mueller, D. C. (1972). A Life Cycle Theory of the Firm. The Journal of Industrial Economics, 20, 199-219. http://dx.doi.org/10.2307/2098055

Nelson, R. R., \& Winter, S. G. (1978). Forces Generating and Limiting Concentration under Schumpeterian Competition. The Bell Journal of Economics, 9, 524-548. http://dx.doi.org/10.2307/3003597

Nkurunziza, J. D. (2005). Credit Can Precipitate Firm Failure: Evidence from Kenyan Manufacturing in the 1990s. United Nations Economic Commission for Africa, CSAE WPS/2005-04.

Pakes, A., \& Ericson, R. (1998). Empirical Implications of Alternative Models of Firms Dynamics. Journal of Economic Theory, 79, 1-45. http://dx.doi.org/10.1006/jeth.1997.2358

Parker, S. C. (2004). The Economics of Self-Employment and Entrepreneurship. Cambridge University Press. http://dx.doi.org/10.1017/CBO9780511493430

Penrose, E. (1959). The Theory of the Growth of the Firm. Oxford: basil Blackwell Publisher.

Persson, H. (2004). The survival and growth of new establishments in Sweden, 1987-1995. Small Business Economics, 23, 423-440. http://dx.doi.org/10.1007/s11187-004-3992-7

Smith, J. (2006). Duration Model Lectures. Retrieved May 2011 from http://www.personal.umich.edu/ econjeff/Courses/ec675_lectures_duration.pdf

Spence, A. M. (1979). Investment Strategy and Growth in a New Market. The Bell Journal of Economics, 10, 1-19. http://dx.doi.org/10.2307/3003316

Strotmann, H. (2006). Enterpreneurial Survival. Small Business Economics.

Wooldridge, J. M. (2002). Econometric Analysis of Cross Section and Panel Data. MIT Press.

Note

Note 1. The models are based on Kiefer (1988), Lancaster (1979 and 1990), Barmby (2001), Wooldridge (2002), Jenkins (2004), and Smith (2006). 